\title{
ERRATUM
}

\section{Hospital charges associated with "never events": comparison of anterior cervical discectomy and fusion, posterior lumbar interbody fusion, and lumbar laminectomy to total joint arthroplasty}

TO THE READERSHIP: An error appeared in our recent article (Daniels AH, Kawaguchi S, Contag AG, et al: Hospital charges associated with never events: comparison of anterior cervical discectomy and fusion, posterior lumbar interbody fusion, and lumbar laminectomy to total joint arthroplasty. J Neurosurg Spine 25:165-169, 2016).

Our paper is an analysis of the State Inpatient Database (SID), a restricted-access, publicly available data set that is maintained by the Agency for Healthcare Research and Quality (AHRQ). One of the provisions of the SID Data Use Agreement (DUA), which we signed when we purchased the data, is that no data observation involving less than or equal to 10 observations is to be published. This measure was put in place by the AHRQ to protect individual patients' privacy and to prevent the potential disclo- sure of personal information. In our published paper, there were some tabulated cells that are in violation of this provision. This error represents an oversight on our part and an inadvertent failure to comply with the Data Use Agreement. For this, we apologize. While we are fully confident that nothing in our paper could be used to identify individuals or their personal information, the fact remains that the disclosures were in violation of the AHRQ guidelines. We have therefore asked the editors of the Journal of Neurosurgery: Spine to post a revised online version of our paper that is in compliance with the AHRQ guidelines, and request that, going forward, authors cite the corrected version of our paper.

The corrected table (Table 2) is shown below.

The article has been corrected online as of April 14, 2017.

Alan H. Daniels, MD

Warren Alpert Medical School of Brown University, Providence, RI

INCLUDE WHEN CITING

Published online April 14, 2017; DOI: 10.3171/2017.3.SPINE15776a.

(c)AANS, 2017

TABLE 2. Charges for patients with uncomplicated versus complicated procedures

\begin{tabular}{|c|c|c|c|c|c|}
\hline Complication & ACDF & PLIF & LL & TKR & THR \\
\hline \multicolumn{6}{|l|}{ None } \\
\hline Patients (\%) & $15,272(97.0)$ & $18,778(95.3)$ & $13,929(91.5)$ & $54,524(96.6)$ & $28,167(96.3)$ \\
\hline Median total charges (\$) & 73,432 & 143,601 & 51,817 & 70,116 & 74,459 \\
\hline 2015 Inflation adjusted (\$) & 80,983 & 158,368 & 57,146 & 77,326 & 82,116 \\
\hline \multicolumn{6}{|l|}{ DVT } \\
\hline Patients (\%) & $94(0.6)$ & $194(1.0)$ & $215(1.4)$ & 709 (1.3) & $284(1.0)$ \\
\hline Median total charges $(x \operatorname{lndex})^{*}$ & $\$ 313,536(4.3)$ & $\$ 284,121(2.0)$ & $\$ 222,455(4.3)$ & $\$ 108,387(1.5)$ & $\$ 126,951(1.7)$ \\
\hline 2015 Inflation adjusted (\$) & 345,779 & 313,339 & 245,331 & 119,533 & 140,006 \\
\hline \multicolumn{6}{|l|}{$\mathrm{PE}$} \\
\hline Patients (\%) & $13(0.1)$ & $46(0.2)$ & $37(0.2)$ & $195(0.3)$ & $56(0.2)$ \\
\hline Median total charges $(x \operatorname{lndex})^{*}$ & $\$ 213,088(2.9)$ & $\$ 246,637(1.7)$ & $\$ 159,566(3.1)$ & $\$ 127,958(1.8)$ & $\$ 143,473(1.9)$ \\
\hline 2015 Inflation adjusted (\$) & 235,001 & 272,000 & 175,975 & 141,117 & 158,227 \\
\hline \multicolumn{6}{|l|}{ SSI } \\
\hline Patients (\%) & $<10$ & $31(0.2)$ & $29(0.2)$ & $344(0.6)$ & $180(0.6)$ \\
\hline Median total charges $(\times \operatorname{lndex})^{*}$ & $\$ 172,967(2.4)$ & $\$ 385,753(2.7)$ & $\$ 196,112(3.8)$ & $\$ 168,964(2.4)$ & $\$ 171,697(2.3)$ \\
\hline 2015 Inflation adjusted (\$) & 190,754 & 425,422 & 216,279 & 186,339 & 189,354 \\
\hline
\end{tabular}

\footnotetext{
* Number indicates multiplier of median charge compared to that in an uncomplicated procedure.
} 